\title{
Erratum zu: Vom Fuße des Himalaya - Wertschöpfungskette Äpfel in Indien
}

\author{
Sabine Golombek ${ }^{1}$ Michael Blanke ${ }^{1}$
}

Online publiziert: 8. Oktober 2020

(c) Der/die Autor(en) 2020

\section{Erratum zu:}

\section{Erwerbs-Obstbau 2020}

https://doi.org/10.1007/s10341-020-00515-9

Durch ein technisches Problem wurde in dem Artikel „Vom Fuße des Himalaya - Wertschöpfungskette Äpfel in Indien" von Sabine Golombek und Michael Blanke die falsche Copyrightzeile eingetragen. Die Copyrightzeile lautet: (C) Der/die Autor(en) 2020.

Der Originalartikel wurde korrigiert.

Funding Open Access funding provided by Projekt DEAL.

Open Access Dieser Artikel wird unter der Creative Commons Namensnennung 4.0 International Lizenz veröffentlicht, welche die Nutzung, Vervielfältigung, Bearbeitung, Verbreitung und Wiedergabe in jeglichem Medium und Format erlaubt, sofern Sie den/die ursprünglichen Autor(en) und die Quelle ordnungsgemäß nennen, einen Link zur Creative Commons Lizenz beifügen und angeben, ob Änderungen vorgenommen wurden.
Die in diesem Artikel enthaltenen Bilder und sonstiges Drittmaterial unterliegen ebenfalls der genannten Creative Commons Lizenz, sofern sich aus der Abbildungslegende nichts anderes ergibt. Sofern das betreffende Material nicht unter der genannten Creative Commons Lizenz steht und die betreffende Handlung nicht nach gesetzlichen Vorschriften erlaubt ist, ist für die oben aufgeführten Weiterverwendungen des Materials die Einwilligung des jeweiligen Rechteinhabers einzuholen.

Weitere Details zur Lizenz entnehmen Sie bitte der Lizenzinformation auf http://creativecommons.org/licenses/by/4.0/deed.de.

Die Online-Version des Originalartikels ist unter https://doi.org/ 10.1007/s10341-020-00515-9 zu finden.

Michael Blanke

mmblanke@uni-bonn.de

1 INRES-Gartenbauwissenschaft, Universität Bonn, Auf dem

Hügel 6, 53121 Bonn, Deutschland 